\title{
Utilizing ecosystem service classifications in multi-criteria decision analysis - Experiences of peat extraction case in Finland
}

\author{
Jyri Mustajoki $^{\mathrm{a}, *}$, Heli Saarikoski ${ }^{\mathrm{a}}$, Valerie Belton ${ }^{\mathrm{b}}$, Turo Hjerppe ${ }^{\mathrm{a}}$, Mika Marttunen ${ }^{\mathrm{a}}$ \\ ${ }^{a}$ Finnish Environment Institute, P.O.Box 140, 00251 Helsinki, Finland \\ b Strathclyde Business School, University of Strathclyde, 199 Cathedral Street, Glasgow G4 0QU, UK \\ * Corresponding author. E-mail: jyri.mustajoki@ymparisto.fi, Tel.: +358-295-251802
}

\begin{abstract}
The Ecosystem Service concept is a widely used framework to examine the links between the functioning of ecosystems and human well-being. There is a broad range of ecosystem services, which are often classified hierarchically as provisioning, regulating and cultural services. MultiCriteria Decision Analysis (MCDA), an approach for analyzing complex problems that involve tradeoffs between multiple objectives, has increasingly been applied in the ecosystem service context. In MCDA, a problem is typically represented hierarchically as a value tree, which resembles the hierarchical structure of the ecosystem service classifications. However, in practice, there are several potential pitfalls that could distort the analysis, if some commonly used ecosystems service classification was directly used as the basis of an MCDA value tree. In this paper, we discuss these potential pitfalls and how to avoid them. Our discussion is illustrated with experience from a case study focusing on the ecosystem services provided by the peatlands in Finland.
\end{abstract}

\section{Introduction}

The Ecosystem Service (ES) concept has become a widely used framework to examine the links between the functioning of ecosystems and human well-being, defined as aspects of ecosystems utilized (actively or passively) to produce human welfare benefits (Fisher et al., 2007; Constanza et al., 2017). Ecosystems offer a broad range of services, which are usually categorized as provisioning, regulating, and cultural services (CICES, 2013; Haines-Young and Potschin, 2013, 2018), and sometimes also supporting and habitat services (MEA, 2003; TEEB, 2008). Applications of the ES concept to concrete land and water management situations usually involve making trade-offs between different ESs, as it is not possible to obtain all services without compromising the availability of some. These situations typically originate from the conflict between provisioning and cultural services, but the trade-offs can also concern provisioning and regulating services (Turkelboom et al., 2018). For example, making use of timber resources (provisioning service) can reduce recreational opportunities (cultural service), but also the capacity of forest to absorb atmospheric carbon (regulating service).

Multi-Criteria Decision Analysis (MCDA) is an umbrella term for structured approaches for analyzing complex problems involving trade-offs between multiple objectives that cannot be attained at the same time (e.g. Belton and Stewart, 2002). It can provide a transparent synthesis of a problem from different perspectives and a systematic evaluation of the alternatives. In MCDA, the problem is typically represented hierarchically in the form of a value tree, in which in the upper level consists of general objectives or criteria (e.g. economic, social and ecological objectives), which can be expanded hierarchically into more detailed sub-criteria. MCDA has been found a useful approach in many environmental management application (Kiker et al., 2005; Huang et al., 2011; Linkov and Moberg, 2011; Keisler and Linkov, 2014; Voinov et al., 2016; Adem Esmail and Geneletti, 2018), and the share of MCDA related papers in the environmental literature has increased fourfold from $0.2 \%$ to $0.8 \%$ during the 21 st century (Cegan et al., 2017). 
In recent years, MCDA has increasingly been applied in the ES context, too (see e.g., Oikonomou et al., 2011; Fontana et al., 2013; Uhde et al., 2015; Favretto et al., 2016; Langemeyer et al., 2016; Saarikoski et al., 2016a). Structurally, the classification systems presented for ESs (e.g. the Common International Classification of Ecosystem Services - CICES, 2013) are similar to the hierarchy of a value tree. However, in practice there are several pitfalls that can distort the analysis if some ES classification was used as such as a basis of the value tree. The main challenge is that the ES concept was originally designed for raising awareness of the multiple ways that human well-being depends on well-functioning ecosystems but it is not necessarily well-suited for a rigorous analysis of the trade-off situations in real-life management and policy decisions (Johnston and Russell, 2011; Saarikoski et al., 2015). In this paper, we discuss how to fit the ES concept into a MCDA framework in a way that still meets the desirable properties of a value tree that seek to ensure the integrity and soundness of the process (e.g. Kirkwood, 2009). For example, a well-structured value tree should be both comprehensive and concise, covering all key aspects of the problem situation while leaving out irrelevant issues (Keeney and Raiffa, 1976; Belton and Stewart, 2002).

The analysis is based on our experiences in applying MCDA, and specifically an MCDA approach called Multi-Attribute Value Theory (MAVT; Keeney and Raiffa, 1976), in integrated assessment and valuation of peatland ecosystem services in Southern Finland. The analysis was motivated by a controversial policy process, the Supplementary Programme for Peatland Protection (Alanen and Aapala, 2015), which incited a debate on the need for biodiversity conservation on one hand, and peat extraction, on the other (Salomaa and Paloniemi, 2014). Although the analysis focuses on the peatland case, the results are also applicable in the other areas of environmental management.

This paper is structured as follows. In Section 2, we describe the basics of MCDA and MAVT including the characteristics of a good value tree. We also describe the different ES classification frameworks in more detail and compare the fundamental differences between MAVT and ES classification hierarchies. In Section 3, we describe the peatland ES assessment case study, and in Section 4, we discuss the experiences of applying the ES framework within the MCDA process of the peatland case. Section 5 concludes the paper.

\section{Methodological background}

\subsection{Multi-attribute value theory}

A typical MAVT process follows the general process of MCDA and it consists of the divergent and convergent phases (see e.g. Kaner et al., 2007; Montibeller et al., 2008; Franco and Montibeller, 2010). The divergent phase aims to enlarge the perspective, so that all the relevant issues would be taken into account in the modeling, whereas the convergent phase aims to provide support for making concise and informed decisions based on the most relevant issues of the problem. The following phases are typically carried out in MCDA processes (see, e.g. Belton and Stewart, 2002):

1. Framing and structuring of the problem including the development of a value tree consisting of criteria and alternatives

2. Evaluating the performances of the alternatives with respect to each criterion

3. Eliciting stakeholders' preferences with respect to criteria and trade-offs between them

4. Evaluating the overall performance of the alternatives with a mathematical model

5. Analyzing the sensitivity of the results to the changes in the model parameters

In MAVT, the preferences of stakeholders are modelled with numerical weights reflecting the acceptable trade-offs between the criteria. The alternatives are evaluated in terms of each of the lowest level criterion (i.e. attribute or performance measure), for example, through field measurements or expert evaluation. Under certain assumptions (Keeney and Raiffa, 1976), an additive model can be used to obtain the overall values for each alternative by multiplying the 
criteria-wise performance scores with corresponding criteria weights and then summing them up. Mathematically, the overall value $v(x)$ of alternative $x$ is

$$
v(x)=\sum_{i=1}^{n} w_{i} v_{i}\left(x_{i}\right),
$$

where $n$ is the number of lowest-level criteria, $w_{i} \in[0,1]$ is the weight of criterion $i$ (normalized so that the sum of weights $w_{i}$ is 1$), x_{i}$ the consequence of alternative $x$ with respect to criterion $i$, and $v_{i}\left(x_{i}\right)$ its performance score on a $0-1$ scale. In practice, the weight assigned to each criterion should reflect how important the stakeholder considers the change in this criterion from its lowest to highest consequence value compared to corresponding changes in the other criteria.

Weights can be elicited with either flat or hierarchical weighting. In flat (or bottom-up) weighting, the weights are assigned directly to the lowest level criteria. In hierarchical (or top-down) weighting, the weights are elicited separately on each level and each branch of the value tree. By normalizing the sum of the weights in each branch to one, one gets the local weight of each criterion under its upper level criterion. The global weight of each lowest level criterion is obtained by multiplying its local weight with the local weights of all its preceding criteria in the value tree. In practice, the weight elicitation can be carried out, for example, by directly asking for the weights, in which case it is important to ensure that the weights also reflect the value ranges of the criteria. Another way is to use a technique, such as Swing (von Winterfeldt and Edwards, 1986), in which the weight elicitation process is specifically designed to ensure the correct interpretation of the weights, for example, by linking the weight elicitation questions explicitly to the weight ranges.

\subsection{Desirable properties of the value tree}

The structuring of the value tree has been described as art (e.g. Winterfeldt, 1980), because there is no unequivocal way to construct it for complex problems which incorporate multiple aspects and considerations. Questions faced in this phase are, for example, what are the criteria to be included in the value tree, what are the upper level criteria and how are the lower-level criteria placed under these, and what is the level of the detail in the description of criteria? Some general principles and structured guidelines are needed for ensuring the integrity of the MCDA process. To support this, many authors have presented lists of desirable properties for the value tree (see e.g. Keeney and Raiffa, 1976; Kirkwood, 1997, 2009; Belton and Stewart, 2002; Eisenführ et al., 2010; Marttunen et al., 2019). The essential elements of these are quite similar and summarised in Table 1.

Table 1. Desirable properties of the value tree.

\begin{tabular}{|c|c|}
\hline 1. Completeness & $\begin{array}{l}\text { - All the concerns of the stakeholders that are needed to evaluate the } \\
\text { overall performance of the alternatives should be included in the model } \\
\text { - The decision context can be adequately described with the criteria }\end{array}$ \\
\hline 2. Minimum size & $\begin{array}{l}\text { - All the criteria should have some impact on the evaluation, i.e. there } \\
\text { should not be irrelevant criteria in the value tree }\end{array}$ \\
\hline 3. Operability & $\begin{array}{l}\text { - Criteria should be meaningful and assessable and the value tree should be } \\
\text { understandable } \\
\text { - The achievement of criteria should be measurable as accurately and } \\
\text { unambiguously as possible } \\
\text { - The value tree should be structured so that the possibility of the biases } \\
\text { related to the weighting process is minimized }\end{array}$ \\
\hline 4. Non-redundancy & $\begin{array}{l}\text { - There should not be overlapping criteria in the value tree, as otherwise } \\
\text { these would be double-counted }\end{array}$ \\
\hline
\end{tabular}




\section{Decomposability and preferential independence \\ It should be possible to determine the scores for each criterion independently, i.e. the performance of an alternative on any selected criterion should not depend on its performance on the other criteria}

The property of completeness refers to the requirement that the value tree should cover all relevant aspects of the problem situation. To that end, value tree is usually constructed in close cooperation with key stakeholders to make sure that it encompasses their key concerns and hence can address the most important trade-off situations between competing goals.

The property of minimum size states that all the criteria should have some impact on the evaluation and there should not be irrelevant criteria in the value tree. However, in practice it is not unambiguous to define whether an criterion is irrelevant, and the major challenge is to find an appropriate balance between completeness and minimal size so that the model is not too complex but still has enough details to capture the nature of the problem. In practice, this depends much on the objectives of the process. That is, if the main objective is to accurately model all the various aspects of the problem, then it may be reasonable to include even very minor details in the model. However, if the aim is to illustrate the main differences between the alternatives to the stakeholders, a too detailed analysis can obscure the key aspects of the problem.

The essence of the operability property is that it is not enough to have a technically sound model, if the users cannot operate it. Also here, a close cooperation with stakeholders in the structuring of the value tree and in the definition of the performance measures for the alternatives can increase their understanding of the model, and consequently their trust in and commitment to the whole process (e.g. Hämäläinen et al., 2010). The operability also means that the measures used for the achievement of the alternatives should be understandable (e.g. Keeney and Gregory, 2005). The operability criterion can also relate to the structure of the value tree so that it would capture the preferences of the stakeholders as accurately as possible. There are many possible biases related to the structure of the value tree that can occur if the value tree is not structured properly (Montibeller and von Winterfeldt, 2015; Marttunen et al., 2018). For example, according to the splitting bias, dividing a criterion into more detailed criteria can increase the weight it receives (Hämäläinen and Alaja, 2008).

The non-redundancy property means that there should not be overlapping criteria in the value tree. This can be violated, for example, in situations, where both direct and indirect effects are included in the model, which leads to double-counting (see e.g. Johnston and Russell, 2011; Saarikoski et al., 2016b). For example, if we include both 'water purifying capacity of the ecosystems' and 'clean water', we succumb to double-counting and even to triple-counting, if we also include recreational activities (such as swimming that depends on clean water) in the model.

Decomposability is a technical property related to the theoretical soundness of the model and is an essential requirement for applying an additive model to elicit the overall values of the alternatives (Keeney and Raiffa, 1976). It states that it should be possible to analyze one criterion at time and the preference on one criterion should not depend on the performance levels of the other criteria. For example, if a person prefers red wine with meat and white wine with fish, the most preferred food and drink cannot be separate criteria in a model of selecting the best meal, as the additional value of $\mathrm{red} / \mathrm{white}$ wine depends on which food is selected (e.g. Bouyssou et al., 2006).

Overall, it may not be possible to achieve all these desirable properties at the same time, but one may have to make choices between them. For example, in addition to balancing between the completeness and minimum size, also the operability property can be in contradiction with completeness as a too detailed model can often be too complicated for being operational. There are also some variations between the desirable property lists presented by different authors. For example, some authors have considered measurability and avoidance of biases as separate properties (e.g. Keeney and Gregory, 2005; Marttunen et al., 2019), whereas here they were dealt 
with under operability. Furthermore, some authors have pointed out that there should also be a balance between the effort needed to construct as high-quality value tree as possible and the resources that are available (e.g. Marttunen et al., 2019).

\subsection{ES classifications}

Various classification frameworks have been developed for assessing ESs, including the Millennium Ecosystem Assessment (MEA, 2003), The Economics of Ecosystem and Biodiversity (TEEB, 2008) and CICES (CICES, 2013). In this paper, we focus on the CICES classification, as it is the most recent one and aims to synthetize the key elements of the other two frameworks.

In CICES, ESs are classified into three sections: 1) provisioning services, 2) regulation and maintenance services and 3) cultural services (see Appendix A). The sections are then separated into divisions describing the main types of output or process, and these are further split into groups on the basis of biological, physical or cultural type or process. The lowest level is the class level, which provides a detailed classification into biological or material outputs and bio-physical and cultural processes that can be linked back to concrete identifiable service sources. The services on the class level can be measured by class type, which are the individual entities of the ESs. For example, flood protection can be classified as follows into these levels:

- Section - regulation and maintenance services

- Division - mediation of flows

- Group - liquid flows

- Class - flood protection

- Class type - e.g. area protected against floods (in $\mathrm{km}^{2}$ ).

One motivation behind CICES compared to the earlier MEA and TEEB classifications is that it tries to avoid the double-counting problem by not having explicit supporting services (Haines-Young and Potchin, 2013). That is, CICES has regulation and maintenance services as one section, whereas MEA has separate regulation services and supporting services sections, and TEEB has regulation services and habitat or supporting services. The CICES hierarchy is also deeper than the other two, as these only have one intermediate level between the section and class levels. There are also some minor differences in the level of detail how the ESs divided into the classes, but in general all these classifications are in accordance with each other.

In our case study, we used the version 4.3 of CICES (Haines-Young and Potchin, 2013). After that an updated version 5.1 of CICES has been published (Haines-Young and Potchin, 2018). Structurally, the updated version is similar to the version we used in our case study, and the main difference is a stronger emphasis on abiotic services. There are also some new classes in the new version, although most of the classes carry over to the new version, and the backward compatibility exists between these. Thus, in general, the conclusions made in this paper of the basis of version 4.3 also apply to the version 5.1 of CICES.

\subsection{Comparison of the ES classification structure with the value tree of MCDA}

The main objective of ES classifications is to provide structured support for mapping and assessing ESs and their impacts on human well-being (MA, 2003). In practice this means providing a comprehensive listing of possible (both monetary and non-monetary) benefits of nature. However, the role of ES classifications in supporting actual decision making has not been clearly articulated (Fisher et al., 2009; Martinez-Harms et al., 2015). In contrast, MCDA is often carried out in a policyrelevant and prescriptive way with an aim to provide systematic and customized support for making informed decisions (e.g. Riabacke et al., 2012).

Due to this background, the hierarchical ES classifications are not ideally designed for supporting rigorous MCDA analysis and especially for meeting desirable properties of the value tree. On the 
other hand, the valuation of ESs is often an important part of the ES assessment process. For example, in the survey of Haines-Young (2016) for CICES users, $37 \%$ of the respondents $(n=125)$ identified "valuation" as a broad application area in which they are working, which was the second highest percentage after $77 \%$ for "mapping and ecosystem assessment" (multiple answers were allowed). In the literature survey of Martinez-Harms at al. (2015), 38\% of the studied cases addressed the assessment of trade-offs between ESs and 19\% prioritization of management actions. All these suggest that the practitioners working with ESs potentially have much interest in applying valuation methods, such as MCDA, in their work.

Of the three main sections of the CICES classification, provisioning services are often related to economic benefits, whereas regulation and maintenance services can often be associated with environmental issues and cultural services with social issues. This trinity of economic, ecological and social issues has also been taken as a basis of the value tree in many environmental MCDA cases including especially those related to the different dimensions or pillars of sustainability (e.g. Dantsis et al., 2010; Pelzer et al., 2012; Karjalainen et al., 2013; Nordström et al., 2013; Salling and Pryn, 2015; Stypka et al., 2016). This similarity might increase the possibility that the CICES classification is used as such as a basis of value tree without fully considering its implications.

Compared to a typical MCDA value tree, the CICES classification is quite deep. Of its levels (section, division, group, class, class type), the section corresponds to the top criteria level of the tree, the class to the lowest criteria level and the class type to the measures used to evaluate the alternatives. The number of different classes is 48 , which includes all the possible identified ESs, and typically only a certain selection of them is relevant to a single case study. Consequently, there might be, for example, only one class under each group. Thus, in many cases it may be reasonable to exclude the division and group levels from the analysis.

\section{Peatland ecosystem service case study}

\subsection{Background}

Peat extraction is a contested topic in Finland where about $5 \%$ of the annual energy production comes from peat. Our project was initiated to support the controversial policy process, the Supplementary Programme for Peatland Protection (Alanen and Aapala, 2015), which incited a debate on the need for biodiversity conservation on one hand, and peat extraction on the other hand. On the local level, there have also been conflicts related to peat extraction of single peatlands mainly because of their negative impacts on water areas, biodiversity and recreation (Albrecht and Ratamäki, 2016). To further intensify the discussion, there has also been debate about the net emissions of peat energy compared to other energy sources, which depends much on the time scale. The renewal time of peat is thousands of years (e.g. Mäkilä, 1997), which is many orders of magnitude larger than a renewal time of forest bioenergy (years or tens of years), but still many orders of magnitude shorter than for coal or oil (millions of years).

\subsection{Outline of the process}

To analyze Finnish peatland policy debate, we carried out a participatory MCDA process together with key stakeholders. The applied method was MAVT with decision analysis interviews (DAIs) (Marttunen and Hämäläinen, 1995, 2008). In the following, we use the term stakeholder to refer to the people representing the nine different parties that were included in the process and whose preferences were analyzed. The research team refers to the core group of four experts and decision analysts from the Finnish Environment Institute that was responsible for carrying out the MCDA process. In addition, a number of external experts of both ecology and peat extraction provided more detailed information to the impact assessment.

In practice, the process consisted of the following phases: 
1) Preliminary work within the research team including the identification and structuring of the problem and its elements (Summer 2016)

2) Stakeholder workshop 1 related to the specification of the case and the related ESs (September 2016)

3) Preliminary assessment of the impacts by the research team (Autumn 2016)

4) Stakeholder workshop 2 related to the assessment of the impacts (December 2016)

5) Preparation of the background material for the DAI to get the stakeholders acquainted with the case and the approach beforehand (Spring 2017)

6) Decision analysis interviews with the stakeholders (Spring-summer 2017)

7) Analysis of the results (including the comparison of the different stakeholders' preference models) in the research team (Summer 2017)

8) One-to-one discussions about the results with stakeholders having opposing views, i.e. different preference order of the alternatives in their individual models (Autumn 2017)

9) Stakeholder workshop 3 related to the analysis of the results and recommendations for the future (December 2017)

Of these, phases 1-5 are described in more detail in Section 3.3 and phases $6-9$ in Section 3.4. In the descriptions, we focus on those parts of the process that are relevant in terms of the application of the ES classification in MCDA process. Thus, we do not discuss, for example, about the contextual results of the analysis (see more detailed discussion in Saarikoski et al., 2019).

\subsection{Structuring of the value tree}

Before any encounter with the stakeholders, preparatory work was carried out in the research group including narrowing the focus to Southern Finland, identifying the four initial alternatives, initial assessment of the impacts, and identification of the stakeholders of the process. The case was not related to an actual decision making situation, but it was a general level strategic assessment of ESs provided by the peatlands. Thus, the stakeholders invited to the process were representatives of relevant businesses, non-governmental organizations and ministries.

The first workshop dealt with the identification of the most relevant ESs. First, the stakeholders were asked to identify the issues that are relevant to the case. To support this, we asked questions like "Why is it important to conserve the peatlands?" and "Why is it important to utilize peat?" we also presented a preliminary list of alternatives and asked "What are the most essential differences between the alternatives?" and "What are the most essential pros and cons of the alternatives?" The identified issues were discussed with the group and mapped onto the CICES classification. After that, we also went through the CICES classification and checked whether it highlighted any other issues that were not yet identified.

Peat as an energy source can be classified somewhere between renewable energy sources and fossil fuels (e.g. Grönroos et al., 2007). It is not explicitly listed in the CICES classification, but it is not in the abiotic complement of CICES either, which includes, for example, fossil fuels. On the other hand, there has also been discussion about whether the abiotic services should be included fully in the CICES classification (e.g. Haines-Young and Potchin, 2013; Haines-Young, 2016; van den Meulen et al., 2016). The new version of CICES (Haines-Young and Potchin, 2018) has indeed increased the role of abiotic services, but peat energy is still not explicitly mentioned under provisioning services, only under regulation services via 'sequestration of carbon in tropical peatlands'. In our case, peat was a core issue, and thus, we decided to include it in our model under provisioning services, which includes a group 'biomass-based energy' (CICES, 2013).

The preliminary list of alternatives presented in the workshop included:

- Conservation, where the peat extraction is reduced by $30 \%$,

- Supplementary proposal for peatland conservation, in which certain peatlands are conserved, but otherwise the peat extraction continues as predicted, 
- Business as usual, in which peat extraction continues according to the prediction of the Technical Research Centre (VTT) of Finland (Later in the process, the name of this alternative was changed to Prediction of VTT as the predicted use differs slightly from the current use),

- Intensified peat extraction, where the peat extraction is increased by $30 \%$.

We asked the stakeholders to comment these, and on the basis of discussion, a new alternative was added to the beginning of the list of the alternatives:

- Conservation+, in which peat extraction is phased out completely by 2030.

The alternatives were named so that Conservation+ was S1, Conservation S2, and the others in the increasing order according to the amount of peat extraction in them.

After the first workshop, an initial impact assessment of the alternatives with regard to the ESs was carried out in the research group. Where possible, we tried to find natural performance measures (Keeney and Gregory, 2005) for the criteria. On some criteria, this was not possible and expert evaluation with a constructed scale from 0 (no or very minor changes) to -4 (very significant negative changes) was used. Impacts on some ESs like flood protection and water purification were found to be negligible. These were listed to be discussed in the next workshop with an aim to confirm whether they could be left out of the analysis.

In the second workshop, we presented the tentative value tree for the case, and for every ES the estimated impacts of the alternatives, which were then discussed. We also showed impact estimates for those ESs that were estimated to be negligible, and after discussion it was decided that most of these should be left out of the analysis. After a few changes the value tree was collaboratively approved. For example, the impacts to ground water were left out of the model, as the peat extraction is already prohibited in the areas of ground water intake.

After the workshop, we compiled background material for the DAls which included: description of the MCDA approach and the background of the case, the value tree to be used and the impact assessments on each ES with necessary background information to support explain these. The final value tree is shown in Figure 1.

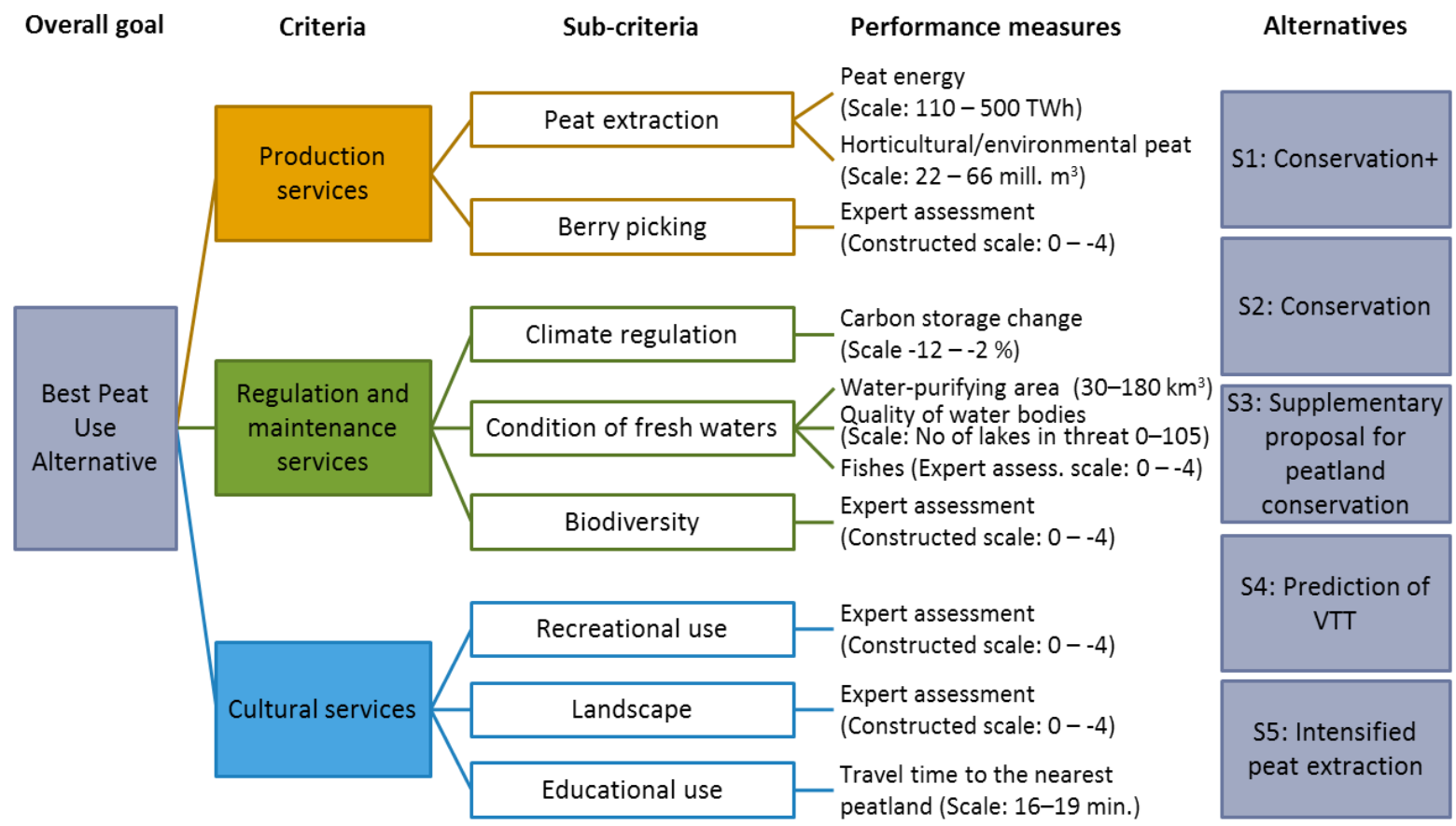

Figure 1. The value tree of the peat extraction case. 


\subsection{Decision analysis interviews and analysis of the results}

The stakeholders' preferences were captured by criteria weights that were elicited with personal DAls using the Swing method. The weights assigned by the interviewed stakeholders for the subcriteria are presented in Figure 2.

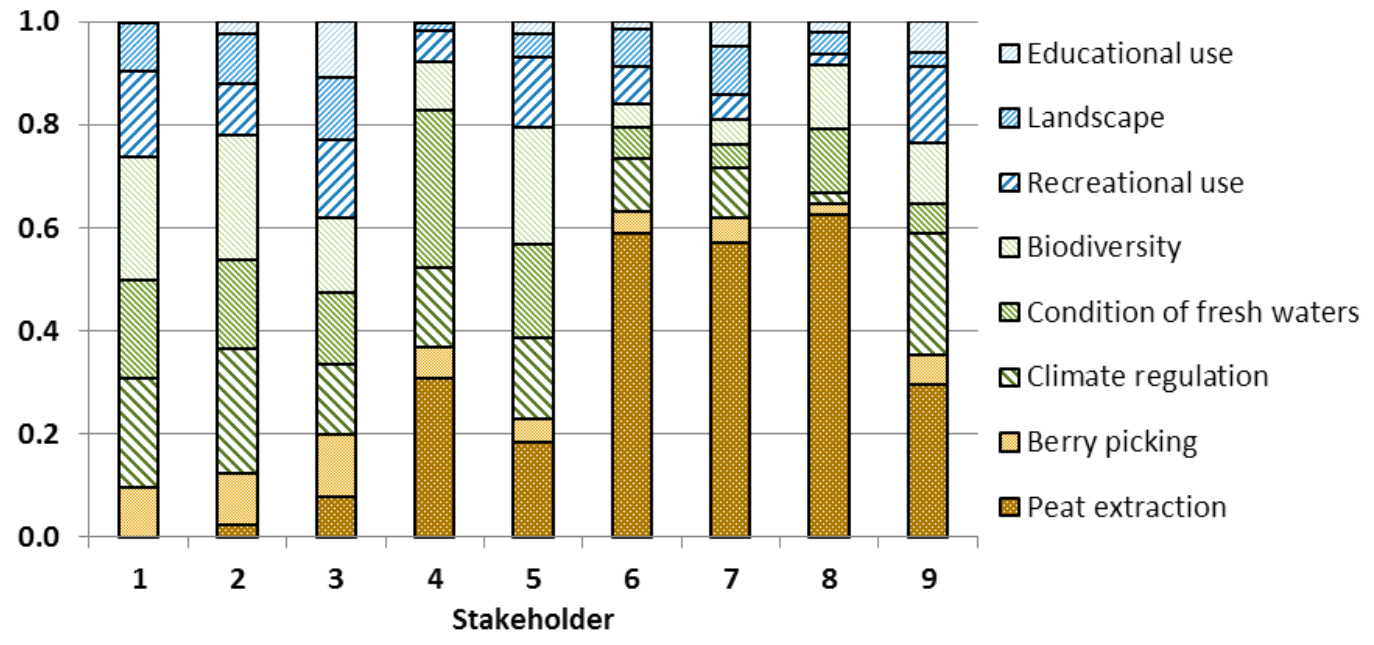

Figure 2. The weights assigned by stakeholders to the different sub-criteria

The applied Excel model provided a visual representation of the resulting overall values of the alternatives, which were discussed together with the stakeholder after the weighting process. After the DAls, their results were analyzed in the research group. We did not use any aggregation of the individual preferences to group preferences, but analyzed them in a comparative way, which is often a better way to illustrate the differences in the opinions and the reasoning behind them (e.g., Belton and Pictet, 1997; Riabacke et al., 2012). Figure 3 presents the overall values of each alternative for each stakeholder.

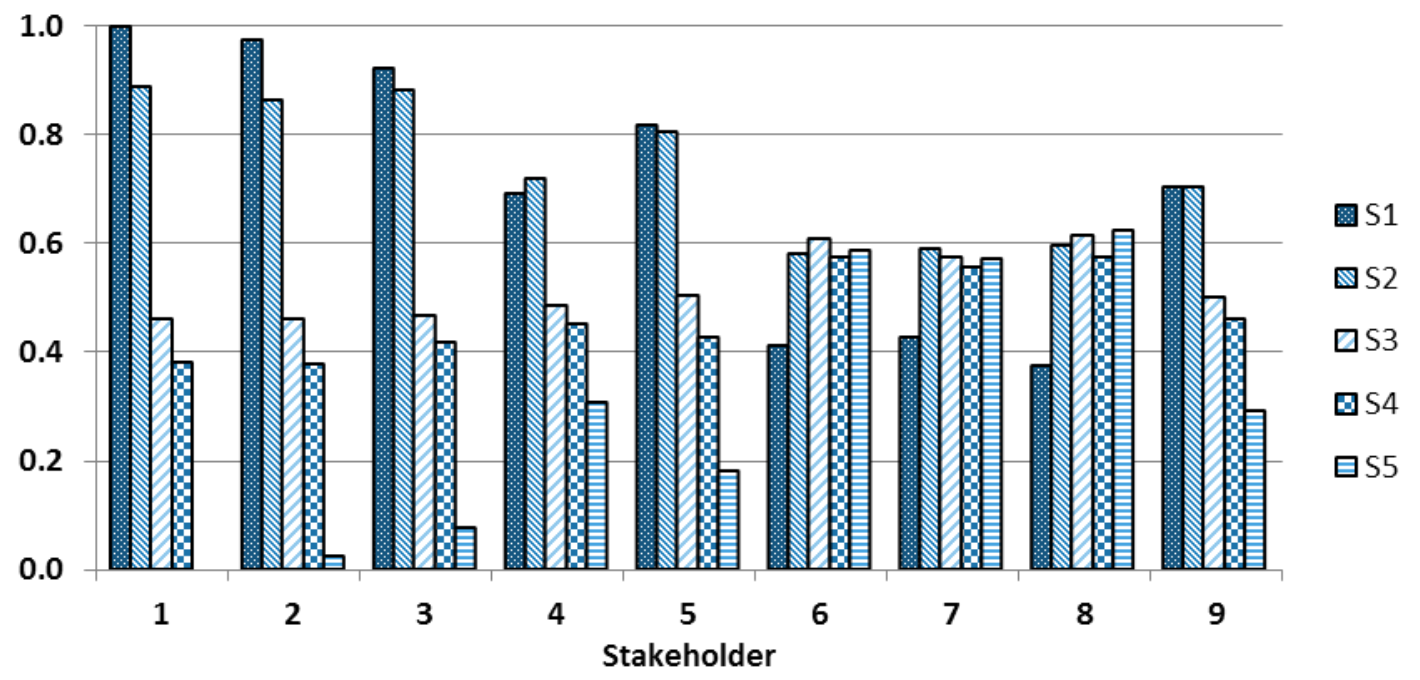

Figure 3. Overall values of the alternatives for each stakeholder.

To communicate the results to the stakeholders, we also arranged discussions in which two stakeholders having opposing views discussed one-to-one about the results. In this way, the stakeholders having the opposing views could personally explain to the other party the reasoning behind their weighting. The final results were presented in a workshop related to the peat extraction debate in Finland, to which all the interviewees were also invited. For the full analysis of the results of the interviews, see Saarikoski et al. (2019). 


\section{Discussion}

Next, we will discuss our experiences of applying the ES classification, and more specifically the CICES classification, within the MCDA framework in our peat extraction case. If not mentioned otherwise, the discussion also applies to the MAE and TEEB classifications, as their structure is quite similar to the CICES classification. The discussion is framed in terms of the possible advantages/disadvantages that promote/hinder the achievement of the desirable properties of the value tree presented in Table 1. The summary of the discussion is presented in Table 2.

Table 2. Summary of the possible advantages and disadvantages of using of the ES classification (and more specifically the hierarchical CICES classification) within the MCDA framework.

\begin{tabular}{|c|c|c|}
\hline Desirable property & Possible advantages & Possible disadvantages \\
\hline $\begin{array}{l}\text { Completeness (1), } \\
\text { minimum size (2) and } \\
\text { a balance between } \\
\text { these }\end{array}$ & $\begin{array}{l}\text { - Acts as a comprehensive } \\
\text { checklist to ensure that all the } \\
\text { issues are considered }\end{array}$ & $\begin{array}{l}\text { - May promote the inclusion of } \\
\text { irrelevant criteria into the value tree } \\
\text { - May still not capture all the relevant } \\
\text { issues, especially the indirect benefits } \\
\text { - May give a false feeling that all the } \\
\text { issues are considered even if they are } \\
\text { not }\end{array}$ \\
\hline Operability (3) & $\begin{array}{l}\text { - Gives a systematic structure for } \\
\text { analyzing the problem } \\
\text { - Provides suggestions for the } \\
\text { measures for estimating the } \\
\text { performance of the criteria }\end{array}$ & $\begin{array}{l}\text { - May decrease innovative thinking in } \\
\text { problem structuring and intuitiveness } \\
\text { of criteria weighting } \\
\text { - May decrease the stakeholders' } \\
\text { feeling of ownership of the problem } \\
\text { as the issues of debate are given as } \\
\text { such from above } \\
\text { - May turn the debate into one on the } \\
\text { grounds of the classifications and } \\
\text { terminology, which can be irrelevant } \\
\text { from the perspective of solving the } \\
\text { case } \\
\text { - May increase the possibility of } \\
\text { behavioral biases in the weighting, if } \\
\text { the classification structure does not } \\
\text { intuitively fit in the case }\end{array}$ \\
\hline $\begin{array}{l}\text { Non-redundancy (4) } \\
\text { and decomposability/ } \\
\text { preferential } \\
\text { independence (5) }\end{array}$ & - None & $\begin{array}{l}\text { - May increase the possibility of } \\
\text { double-counting of criteria }\end{array}$ \\
\hline
\end{tabular}

\subsection{Completeness, minimum size and a balance between these}

In terms of completeness, the CICES classification was helpful as a comprehensive checklist to make sure that all ESs were considered in the initial stages of the process. Most of the ESs listed by CICES were identified by the stakeholders in the first 'free thinking' identification exercise, and it was relatively easy to relate these to the CICES table (Appendix A) although the terminology used by the stakeholders was somewhat different. For example, the stakeholders used the term 'recreational services' to refer to 'experiential use of plants, animals and land-/seascapes in different environmental settings'. 
The good match with the ESs listed in CICES and the criteria identified by the stakeholders can be explained by the stakeholders' involvement in previous peatland policy processes that had made use of the ES concept (see Primmer et al., 2018). Some of the CICES categories such as 'breeding places and shelter for plants and animals' were relevant to the peatland case but they were not included as such in our analysis because they were covered by the criteria 'plants and animals' (cloudberries and cranberries, game, fish, etc.). Including the regulating services that maintain provisioning services like fish and berries would also have led to double-counting (see also Section 4.3). This was intuitively clear to the stakeholders who listed birds, game and fish as criteria but not the ecological conditions and structures that support them.

The downside of first identifying a detailed list of ESs was that it made it easy for the stakeholders to suggest adding such criteria in the value tree that eventually were quite insignificant for this case. For example, mushrooms, cosmetics products, and also cultural heritage were all included in the initial value tree, but omitted from the final value tree due to the negligible impacts of peat extraction on them. However, before excluding them, we had to find evidence on the lack of their importance. This turned out to be quite laborious, as studies showing that some issue is unimportant are much more uncommon than studies highlighting the important issues. We also tried not to simplify the analysis too much by excluding too many criteria and therefore we included some criteria like 'education', prompted by the CICES and cultural ES literature. However, most stakeholders assigned it very little weight, thereby confirming that the role of peatlands in providing opportunities for learning about nature is not a decisive issue in the peatland debate.

On the other hand, CICES did not capture all central aspects of the debate. Most importantly, energy from peat is not explicitly listed as an example of group 'biomass based sources of energy', but it was a central provisioning service in our case study. Some studies have not considered peat as an ecosystem service because its extraction irreversibly destroys ecosystems and their capacity to provide other services (Bullock et al., 2012). However, in our case, excluding energy and horticultural peat from the analysis would have made it policy-irrelevant because the debate centers around peat extraction vs. other ecosystem services derived from the peatlands.

We also observed that CICES does not sufficiently take into account indirect benefits from provisioning services. In this case, the stakeholders put a lot of emphasis on the employment opportunities and stable regional development provided by energy and horticultural peat extraction. They were invited to adjust the weight assigned to the peat energy by assuming that its impact range also includes these indirect effects. However, in practice, it was quite a challenging task to consider all these aspects simultaneously under a single criterion. A similar finding was made by Proctor and Drechsler (2006), who actually also included social criteria (such as jobs) and economic criteria (such as costs and benefits) in their analysis of ecosystem services in a recreational area in Australia. Another missing, but essential, aspect was the question of land owner rights, which in our case was a key consideration, as much of the discussion around the Supplementary Programme for Peatland Protection had focused on the question of voluntary vs. government imposed protection programmes.

\subsection{Operability}

Operability of the model includes issues such as how well the structure of the value tree describes the nature of the problem, how understandable are the model and the results, and how easy the approach is to use with stakeholders. The structuring of the value tree is often an iterative process, which can enrich stakeholders' thinking (Gregory et al., 2012). However, a rigorous use of an ES classification as a basis of the value tree does not allow any room for restructuring the tree according to the needs of the case. Consequently, it can weaken the innovative thinking in problem structuring, especially as the structure of the ES classification is unfamiliar to most people. 
Another weakness of having a pre-defined value tree is that it may reduce the stakeholders' feeling of ownership of the problem. When a value tree is iteratively created together with stakeholders, they can easily see their influence in the evolution of the structure in terms of the concrete issues that are added in the value tree. In contrast, when starting from a very large pre-defined structure such as CICES, the main task of the stakeholders is to eliminate the irrelevant issues from the list of criteria. Then, the issues remaining in the value tree have not come from the stakeholders themselves, but are given as such to them.

In practice, the nature of our peatland case can be characterized by energy and horticultural peat versus other criteria. For example, the alternative S5 was the best alternative in peat energy production, but the worst in every other criterion, whereas for the alternative S1 these were vice versa. In this respect, one possible way to structure the value tree would have been to place peat extraction in one branch and the other issues in another. In the applied CICES structure, peat was classified under provisioning services, which also includes other products such as the berries. Consequently, many stakeholders had problems in eliciting weights for the provisioning services, as it included such different criteria. Actors who favored peat extraction generally disregarded berries as insignificant while actors who preferred peatland protection considered berries far more important than peat, especially energy peat.

Having conflicting criteria in the same branch of the value tree can also cause loss of intuitiveness especially in hierarchical weighting. That is, when eliciting the top level weights with the Swing method, one has to compare situation in which both peat extraction and berry production are on their lowest level to a situation in which they are on their highest level, which in practice is an impossible situation. This leads to comparing unrealistic alternatives, which might confuse the person eliciting the weights. In this respect, an ideal situation would be that for each branch, there is an alternative that is the worst in all the criteria of this branch and also an alternative that is the best in all the criteria. This observation is good to keep in mind also in non-ES related situations, and it has received surprisingly little attention in the literature.

An operational value tree is also suggested to be balanced so that different branches of the value tree are approximately of the same size (see e.g. Marttunen et al., 2018). However, we emphasize that besides "visual balance", where the value tree does not seem to be visually tilted in any direction, it is also important to consider "contextual balance", where the issues are in balance in terms of their relevance to the case. Of course, the degree of relevance typically varies among the stakeholders. In our case, peat was in the very core of the case, and for some interviewees, its advantages in energy production alone were enough to cancel off its disadvantages. In this respect, it would have been justifiable to even have such value tree in which peat production alone would form one branch of the value tree.

Flat (i.e. non-hierarchical, bottom-up) weighting (in which the weights are assigned directly to the lowest level criteria instead of assigning them hierarchically to each branch of the value tree) is one way to deal with the difficulty of eliciting weights on the upper level (e.g. Marttunen et al., 2018). However, if the number of ES classes in the model is high, the flat weighting might be prone to biases in which the weights of the most important criteria are underestimated, and of the least important criteria overestimated (e.g. Jacobi and Hobbs, 2007; Hämäläinen and Alaja, 2008; Montibeller and von Winterfeldt, 2015; Marttunen et al., 2018). For example, in our case, some interviewees had a strong view about the advantages of peat extraction despite the negative impacts on other ESs. Although peat was assigned 100 points in Swing weighting, the large number of other ESs (altogether seven) meant that the total sum of the weights of these services exceeded the weight of peat, even if the interviewees gave a relatively low weight (10-30 points) to these services. We attempted to avoid this bias by checking the assigned weights so that we calculated the total number of points assigned to the other ESs than peat and asked the interviewee to confirm whether these reflect his/her preferences. For some stakeholders, this cross-checking led him/her to make some modifications to the weights. 
It has also been suggested that compensation between the three main sections of ESs is not even appropriate (Segura et al., 2015). In this respect, applicable approaches include ones in which the weights for highest level criteria are not explicitly given, but the results are presented in terms of showing best alternative for each weight combination. A visual approach for this is the SMAA-like (Stochastic Multi-objective Acceptability Analysis; Lahdelma et al., 1998) analysis, which presents a graph on the weight space having separated areas for each alternative being best one (see also Hodgkin et al., 2005). This kind of a graph only allows the use of three dimensions, which, however, appositely suits for analyzing three main sections of ESs. In this approach, the stakeholders can analyze, for example, with which weight combinations a certain alternative is the best one, and then consider whether these combinations are acceptable. Another applicable approach would be to present the results separately for each three main sections. Then the results can be visualized e.g. by presenting three parallel bars for each alternative representing the overall values under each main section.

Measurability of the criteria is one element of operability. According to Keeney and Gregory (2005), performance measures for measuring the criteria should be unambiguous, comprehensive (with respect to the range covering all the possible consequences), direct, operational and understandable. In this respect, the CICES classification is expected to help defining the measures, as it provides suggestions for class types for measuring each class, and also examples for what should be taken into account under each class. Of course, the measurability also depends much about the means to measure the performance of the service, and the availability of the data. For example, in our case, especially on the cultural services, we had to use experts to assess the impacts of the alternatives.

One problem with the CICES classification is that it considers biodiversity as a cultural service while most participants intuitively felt that it is a regulating service, linking it to an ecological aspect of the peatland policy dilemma. The categories 'physical and experiential interactions' and 'intellectual and representative interactions' were also not clear to the participants but the classes such as 'educational and aesthetic use of peatlands' made sense to them. The classes 'existence and bequest values' were brought up by the participants in the identification exercise but we did not include them in the value tree because it would have been difficult to operationalize them (see Saarikoski et al., 2016b). Instead, these were value arguments that were used by the participants when defending the importance of biodiversity. Overall, all these ambiguities can decrease the intuitiveness of the weighting process, especially in hierarchical weighting, as it might be difficult to give weights without clearly knowing what issues should be considered in the weighting. Actually, this was a reason that we finally ended up using non-hierarchical (i.e. flat) weighting, in which weights are assigned directly to the different ES classes (sub-criteria level in Figure 1).

\subsection{Non-redundancy and decomposability/preferential independence}

One of the known problems of using an ES classification with MCDA is double-counting (see, e.g. Fisher et al., 2009; Liu et al., 2013), which is directly related to non-redundancy. This is, however, not only related to the use of MCDA with ESs, but it has been also noticed in application of ESs in general (e.g. Saarikoski et al., 2015; Haines-Young, 2016), and with respect to application of economic valuation methods such as Cost-Benefit Analysis in particular (e.g. Fisher et al., 2009; Fu et al., 2011; Johnston and Russell, 2011). The double-counting concerns all the ES classifications (MA, 2003; TEEB, 2008; CICES, 2013), as none of them distinguishes between intermediate ecosystem processes and the services that are directly consumed or enjoyed by people (Boyd and Banzhaf, 2007; Fisher and Turner 2008). Although CICES aims to reduce double-counting by deliberately excluding supporting services, it does include categories such as 'maintaining nursery populations and habitats' and 'filtration/sequestration/storage/accumulation by ecosystems' as regulating services. Doublecounting cannot be avoided, if the value tree covers both these ecological structures and processes which help maintaining plant and animal populations (e.g. berries and fish) and purify natural 
waters, and the plants and animals, and good water quality, maintained by these structures and processes. Several authors suggest that a rigorous analysis should focus only the final products produced by ESs, especially in the valuation context (e.g. Johnston and Russell, 2011).

In our case, water purification is a regulating service, but it also has direct impacts on the quality of drinking water, which is a provisioning service, and the quality of water bodies, which influence recreational opportunities (cultural service). Therefore, we only included criterion 'quality of water bodies' in the value tree. Nevertheless, we did not quite succeed in avoiding double-counting. Under criterion 'condition of fresh waters' we had three sub-criteria, which essentially measured the same thing, namely the quality of water: 'water purification by peatlands', 'quality of water bodies' (measured by the number of lakes in a threat of decreasing quality), and 'impacts on fish and crawfish'. The first criterion was included because in ecosystem service literature it is often expected that peatlands have an important function in filtering and purifying waters that run through them (Biancalani and Avagyan, 2014). However, it turned out that the peatlands in our alternatives did not really have this role, mostly because most of the minerotrophic peatlands, which play a role in filtering phosphorous and nitrogen from waters running through them, are located in Northern Finland. The ones in Southern Finland are mostly cut off by ditches, and hence, they have lost their water purifying capacity.

Another example of double-counting in our value tree was berry picking. Berries, especially cloudberries, are an important provisioning service especially in Northern Finland, where they are also picked for commercial uses. However, in Southern Finland, berry picking is mostly carried out as a recreational activity. It is quite likely that some interviewees put emphasis on the berries because it was considered as both production service and cultural service through its recreational aspects. For instance, one person who assigned a relatively high weight to berries argued that berry picking is good exercise which motivates family outings in the nature. Some interviewees also complained that it was artificial and not commonsensical to try to separate the different aspects of berry picking, the berry yield as a provisioning service and the experience of picking berries in the nature as a recreational service.

The additive MAVT models are also assumed to be decomposable and they also assume preferential independence of the criteria. In our case, it was difficult for some interviewees to only consider the energy obtained from peat without simultaneously considering the disadvantages of peat extraction. However, this phenomenon is not only an issue of our case, but is a generally acknowledged challenge of MAVT (e.g. Morton, 2017). Thus, it is likely that the weighting would have been equally difficult for those interviewees, even if the ES classification had not been used. There are also approaches to reduce the possibility of double-counting, for example, by using means-ends networks (Keeney, 1992) to identify relationships between the fundamental objectives and means objectives to achieve them. These approaches are applicable regardless of the application area, and thus, also here within the ESS framework.

\section{Conclusions}

In this paper, we studied the use of the ES classification, in particular CICES, as a starting point for a value tree in MCDA. Based on the literature, we first identified the characteristics of a good value tree, and then conducted a case study focusing on the ESs provided by the peatlands in Finland to systematically evaluate the applicability of the developed ES framework in MCDA. In general, we think that building a value tree on the ES classification increases the possibility of value trees becoming too detailed rather than too simple. A similar observation has also been made elsewhere, for example, Marttunen et al. (2018) have discussed problems related to very large hierarchies. On the other hand, although the ES classification aims to be comprehensive, it still excludes some important aspects in natural resources use. For example, in our case there were some important 
indirect impacts to the society (e.g. employment and local economy) that were highly relevant issues, but that were missing from the ES classification (see also Karjalainen et al., 2013).

Another disadvantage of using the ES classification as a basis of the value tree is that it can lead to the rigidity of the modeling and in this way to decrease the operability and understandability of the value tree. In this respect, we suggest considering the classification only as tentatively, and allowing room for modification of the value tree and its elements according to the needs of the case. The strict use of the ES classification as a basis of the value tree can also increase the possibility of double-counting. Countermeasures for that include proper definition of what we mean by each ES and careful identification of possible situations of double-counting and planning the set of criteria according to that.

Overall, our analysis showed that the ES classification can be used as a supportive element in the identification of the problem and its elements in MCDA. However, one should be aware of the potential pitfalls in the use of MCDA and realize its application in a careful way which seeks to ensure that potential pitfalls are avoided and results are not distorted. One possible process could be a compromise approach, which starts with the ES classification, but allows modifications during the process. Actually, as an epilogue to our modeling process, we continued our process using this kind of an approach by making some modifications to the initial value tree after the DAls, with an aim to improve the model to meet the desirable properties of the value tree. First, we added a new upper level class of 'other criteria' that included issues related to the local economy, employment and land ownership. Secondly, we split the sub-criterion 'peat extraction' into two separate subcriteria: 'peat energy' and 'horticultural/environmental peat'. We also asked the participants to carry out the weighting again with this new model (for details, see Saarikoski et al., 2019). Many of them indeed assigned relatively high weights for these newly added criteria, which supported their inclusion into our model. Most of the participants also thought that the new model better represents the wide range of relevant issues.

\section{Acknowledgements}

This work has been supported by the ValuES project (Potential and Pitfalls of Alternative Approaches to Ecosystem Service Valuation: Developing an Integrated Valuation Framework) funded by the Academy of Finland under Grant agreement no. 275772.

\section{References}

Adem Esmail, B., Geneletti, D. (2018). Multi-criteria decision analysis for nature conservation: A review of 20 years of applications. Methods in Ecology and Evolution, 9(1), 42-53.

Alanen, A., Aapala, K. (eds.) (2015). Proposal of the Mire Conservation Group for supplemental mire conservation. Reports of the Ministry of the Environment 26/2015, pp. 175. (In Finnish)

Albrecht, E., Ratamäki, O. (2016). Effective arguments for ecosystem services in biodiversity conservation - A case study on Finnish peatland conservation, Ecosystem Services, 22, 41-50.

Belton, V., Pictet, J. (1997). A framework for group decision using a MCDA model: sharing, aggregating or comparing individual information? Journal of Decision Systems, 6 (3), 283-303.

Belton, V., Stewart, T. (2002). Multiple Criteria Decision Analysis - An Integrated Approach. Kluwer, Boston, U.S.A.

Biancalani, R. Avagyan, A. (Eds.) (2014). Towards climate-responsible peatlands management. Food and Agiculture Organization of the United Nations (FAO), Rome, Italy. 
Boyd, J., Banzhaf, S. (2007). What are ecosystem services? The need for standardized environmental accounting units. Ecological Economics, 63, 616-626.

Bouyssou, D., Marchant, T., Pirlot, M., Tsoukiàs, A., Vincke, P. (2006). Evaluation and Decision Models with Multiple Criteria. Stepping Stones for the Analyst. Springer Science+Business Media, Inc., N.Y.

Bullock, C.H., Collier, M.J., Convery, F. (2012). Peatlands, their economic value and priorities for their future management - The example of Ireland. Land Use Policy, 29, 921-928.

Cegan, J.C., Filion, A.M., Keisler, J.M., Linkov, I. (2017). Trends and applications of multi-criteria decision analysis in environmental sciences: Literature review. Environment Systems and Decisions, 37(2), 123-133.

CICES (2013). The Common International Classification of Ecosystem Services (CICES) V4.3. January 2013. http://cices.eu/

Costanza, R., de Groot, R., Braat, L., Kubiszewski, I., Fioramonti, L., Sutton, P., Farber, S., Grasso, M. (2017). Twenty years of ecosystem services: How far have we come and how far do we still need to go? Ecosystem Services, 28, 1-16.

Dantsis, T., Douma, C., Giourga, C., Loumou, A., Polychronaki, E.A. (2010). A methodological approach to assess and compare the sustainability level of agricultural plant production systems. Ecological Indicators, 10, 256-263.

Eisenführ, F., Weber, M., Langer, T. (2010). Rational Decision Making. Springer, Berlin.

Favretto, N., Stringer, L.C., Dougill, A.J., Dallimer, M., Perkins, J.S., Reed, M.S., Atlhopheng, J.R., Mulale, K. (2016). Multi-Criteria Decision Analysis to identify dryland ecosystem service tradeoffs under different rangeland land uses. Ecosystem Services, 17, 142-151.

Fisher, B., Costanza, R., Turner, R.K., Morling, P. (2007). Defining and Classifying Ecosystem Services for Decision Making. CSERGE Working Paper EDM, No. 07-04.

Fisher, B., Turner, R.K., (2008). Ecosystem services: classification for valuation. Biological Conservation, 141, 1167-1169.

Fisher, B., Turner, R.K., Morling, P. (2009). Defining and classifying ecosystem services for decision making. Ecological Economics, 68, 643-653.

Fontana, V., Radtke, A., Bossi Fedrigotti, V., Tappeiner, U., Tasser, E., Zerbe, S., Buchholz, T. (2013). Comparing land-use alternatives: Using the ecosystem services concept to define a multicriteria decision analysis. Ecological Economics, 93, 128-136.

Franco, L.A., Montibeller, G. (2010). Facilitated modelling in operational research. European Journal of Operational Research, 205, 489-500.

Fu, B.-J., Su, C.-H., Wei, Y.-P., Willett, I.R., Lü, Y.-H., Liu, G.-H. (2011). Double counting in ecosystem services valuation: causes and countermeasures. Ecological Research, 26, 1-14.

Gregory, R., Failing, L., Harstone, M., Long, G., McDaniels, T., Ohlson, D. (2012). Structured Decision Making: A Practical Guide to Environmental Management Choices. Wiley-Blackwell, Chichester, UK.

Grönroos, J., Seppälä, J., Koskela, S., Kilpeläinen, A., Leskinen, P., Holma, A., Tuovinen, J.-P., Turunen, J., Lind, S., Maljanen, M., Martikainen, P.J. (2013). Life-cycle climate impacts of peat fuel: calculation methods and methodological challenges. The International Journal of Life Cycle Assessment, 18(3), 567-576. 
Haines-Young, R. (2016). Support to EEA tasks under the EU MAES process. Negotiated procedure No EEA/NSS/16/002. Report of Results of a Survey to Assess the Use of CICES, 2016 (Deliverable 2). European Environment Agency.

Haines-Young, R., Potchin, M. (2013). Common International Classification of Ecosystem Services (CICES): Consultation on CICES Version 4, August-December 2012. Revised January 2013. Report to the European Environment Agency. EEA Framework Contract No EEA/IEA/09/003. https://unstats.un.org/unsd/envaccounting/seearev/GCComments/CICES_Report.pdf

Haines-Young, R., Potchin, M. (2018). Common International Classification of Ecosystem Services (CICES) V5.1. Guidance on the Application of the Revised Structure. https://cices.eu/content/uploads/sites/8/2018/01/Guidance-V51-01012018.pdf

Hämäläinen, R.P., Alaja, S. (2008). The threat of weighting biases in environmental decision analysis. Ecological Economics, 68, 556-569.

Hämäläinen, R.P., Mustajoki, J., Marttunen, M. (2010). Web-based decision support: Creating a culture of applying multi-criteria decision analysis and web supported participation in environmental decision making. In Rios-Insua D., French S. (eds): e-Democracy: A Group Decision and Negotiation Perspective. Advances in Group Decision and Negotiation 5, Springer Science+Business Media B.V., Dordrecht, Holland, 201-221.

Hodgkin, J., Belton, V., Koulouri, A. (2005). Supporting the intelligent MCDA user: A case study in multi-person multi-criteria decision support. European Journal of Operational Research, 160, 172-189.

Huang, I.B., Keisler, J., Linkov, I. (2011). Multi-criteria decision analysis in environmental sciences: ten years of applications and trends. Science of the Total Environment, 409, 3578-3594.

Jacobi, S. K., Hobbs, B.F. (2007). Quantifying and mitigating the splitting bias and other value treeinduced weighting biases. Decision Analysis, 4, 194-210.

Johnston, R.J., Russell, M. (2011). An operational structure for clarity in ecosystem service values. Ecological Economics, 70, 2243-2249.

Kaner, S., Lind, L., Toldi, C., Fisk, S., Berger, D. (2007). Facilitator's Guide to Participatory DecisionMaking. Second Edition. Jossey-Bass/John Wiley \& Sons, Inc., San Francisco, CA, U.S.A.

Karjalainen, T.P., Marttunen, M., Sarkki, S., Rytkönen, A.-M. (2013). Integrating ecosystem services into environmental impact assessment: An analytic-deliberative approach. Environmental Impact Assessment Review, 40, 54-64.

Keeney, R.L. (1992). Value-Focused Thinking: A Path to Creative Decisionmaking. Harvard University Press, Cambridge, MA, U.S.A.

Keeney, R.L., Gregory, R.S. (2005). Selecting attributes to measure the achievement of objectives. Operations Research, 53(1), 1-11.

Keeney, R.L., Raiffa, H. (1976). Decisions with Multiple Objectives - Preferences and Value Tradeoffs. Wiley, New York, U.S.A.

Keisler, J., Linkov, I. (2014). Environment models and decisions. Environment Systems and Decisions, 34, 369-372.

Kiker, G.A., Bridges, T.S., Varghese, A., Seager, T.P., Linkov, I. (2005). Application of multicriteria decision analysis in environmental decision making. Integrated Environmental Assessment and Management, 1(2), 95-108.

Kirkwood, (1997). Strategic Decision Making: Multi-Objective Decision Analysis with Spreadsheets. Duxbury Press, Belmont, CA, U.S.A. 
Kirkwood, G.W. (2009). Decision analysis. In Sage, A.P., Rouse, W.B. (eds.): Handbook of Systems Engineering and Management, 2nd ed. John Wiley \& Sons, Inc., New Jersey, 1223-1249.

Lahdelma, R., Hokkanen, J., Salminen, P. (1998). SMAA - Stochastic multiobjective acceptability analysis. European Journal of Operational Research, 106(1), 137-143.

Langemeyer, J., Gómez-Baggethun, E., Haase, D., Scheuer, S., Elmqvist, T. (2016). Bridging the gap between ecosystem service assessments and land-use planning through Multi-Criteria Decision Analysis (MCDA). Environmental Science \& Policy, 62, 45-56.

Linkov, I., Moberg, E. (2011). Multi-criteria decision analysis: environmental applications and case studies. CRC Press, Boca Raton, Florida.

Liu, S., Crossman, N.D., Nolan, M., Ghirmay, H. (2013). Bringing ecosystem services into integrated water resources management. Journal of Environmental Management, 129, 92-102.

Mäkilä, M. (1997). Holocene lateral expansion, peat growth and carbon accumulation on Haukkasuo, a raised bog in southeastern Finland. Boreas, 26, 1-14.

Martinez-Harms, M.J., Bryan, B.A., Balvanera, P., Law, E.A., Rhodes, J.R., Possingham, H.P., Wilson, K.A. (2015). Making decisions for managing ecosystem services. Biological Conservation, 184, 229-238.

Marttunen, M., Hämäläinen, R.P. (1995). Decision analysis interviews in environmental impact assessment. European Journal of Operational Research 87, 551-563.

Marttunen, M., Hämäläinen, R.P. (2008). The decision analysis interview approach in the collaborative management of a large regulated water course. Environmental Management, 42, 1026-1042.

Marttunen, M., Belton, V., Lienert, J. (2018). Are objectives hierarchy related biases observed in practice? A meta-analysis of environmental and energy applications of Multi-Criteria Decision Analysis. European Journal of Operational Research, 265(1), 178-194.

Marttunen, M., Haag, F., Belton, V., Mustajoki, J., Lienert, J. (2019). Methods to inform the development of concise objectives hierarchies in multi-criteria decision analysis. European Journal of Operational Research, 277(2), 604-620.

MEA (2003). Ecosystems and Human Well-being. A Framework for Assessment. A Report of the Conceptual Framework Working Group of the Millennium Ecosystem Assessment. Island Press, Washington, U.S.A. http://www.millenniumassessment.org/en/Framework.html

Montibeller, G., von Winterfeldt, D. (2015). Cognitive and motivational biases in decision and risk Analysis. Risk Analysis, 35, 1230-1251.

Montibeller, G., Belton, V., Ackermann, F., Ensslin, L. (2008). Reasoning maps for decision aid: an integrated approach for problem-structuring and multi-criteria evaluation. Journal of the Operational Research Society, 59, 575-589.

Morton, A. (2017). Multiattribute value elicitation. In Dias, L.C., Morton, A., Quigley, J. (eds.): Elicitation: The Science and Art of Structuring Judgement. Springer, New York.

Nordström, E.-M., Holmström, H., Öhman, K. (2013). Evaluating continuous cover forestry based on the forest owner's objectives by combining scenario analysis and multiple criteria decision analysis. Silva Fennica, 47(4), 1-22.

Oikonomou, V., Dimitrakopoulos, P.G., Troumbis, A.Y. (2011). Incorporating ecosystem function concept in environmental planning and decision making by means of multi-criteria evaluation: The case-study of Kalloni, Lesbos, Greece. Environmental Management, 47, 77-92. 
Pelzer, E., Fortino, G., Bockstaller, C., Angevin, F., Lamine, C., Moonen, C., Vasileiadis, V., Guérin, D., Guichard, L., Reau, R., Messéan, A. (2012). Assessing innovative cropping systems with DEXiPM, a qualitative multi-criteria assessment tool derived from DEXi. Ecological Indicators, $18,171-182$.

Primmer, E., Saarikoski, H., Vatn, A. (2018). An empirical analysis of institutional demand for valuation knowledge. Ecological Economics, 152, 152-160.

Proctor, W., Drechsler, M. (2006). Deliberative multicriteria evaluation. Environment and Planning C: Government and Policy, 24, 169-190.

Riabacke, M., Danielson, M., Ekenberg, L. (2012). State-of-the-art in prescriptive criteria weight elicitation. Advanced Decision Sciences, pp. 24.

Saarikoski, H., Jax, K., Harrison, P.A., Primmer, E., Barton, D.N., Mononen, L., Vihervaara, P., Furman, E. (2015). Exploring operational ecosystem service definitions: The case of boreal forests. Ecosystem Services, 14, 144-157.

Saarikoski, H., Barton, D.N., Mustajoki, J., Keune, H., Gomez-Baggethun, E., Langemeyer, J. (2016a). Multi-criteria decision analysis (MCDA) in ecosystem service valuation. In: Potschin, M., Jax, K. (Eds.): OpenNESS Ecosystem Services Reference Book. EC FP7 Grant Agreement no. 308428.

Saarikoski, H., Mustajoki, J., Barton, D., Geneletti, D., Langemeyer, J., Gomez-Baggethun, E., Marttunen, M., Antunes, P., Keune, H., Santos, R. (2016b). Multi-Criteria Decision Analysis and Cost-Benefit Analysis: Comparing alternative frameworks for integrated valuation of ecosystem services. Ecosystem Services, 22, 238-249.

Saarikoski, H., Mustajoki, J., Hjerppe, T., Aapala, K. (2019). Participatory Multi-Criteria Decision Analysis in Valuing Peatland Ecosystem Services. Ecological Economics, 162, 17-28.

Salling, K.B., Pryn, M.R. (2015). Sustainable transport project evaluation and decision support: indicators and planning criteria for sustainable development. International Journal of Sustainable Development \& World Ecology, 22(4), 346-357.

Salomaa, A., Paloniemi, R. (2014). Ecosystem services, voluntariness and mire conservation. Suo, 65(1), 1-15. (In Finnish)

Segura, M., Maroto, C., Belton, V., Ginestar, C. (2015). A new collaborative methodology for assessment and management of ecosystem services. Forests, 6, 1696-1720.

Stypka, T., Flaga-Maryańczyk, A., Schnotale, J. (2016). Application of the AHP method in environmental engineering: Three case studies. In: De Felice, F., Saaty, T.L., Petrillo, A., Applications and Theory of Analytic Hierarchy Process - Decision Making for Strategic Decisions. InTech, 55-87.

TEEB (2008). The Economics of Ecosystem and Biodiversity (TEEB). http://www.teebweb.org/resources/ecosystem-services/

Turkelboom, F., Jacobs, S., Leone, M., Kelemen, E., García-Llorente, M., Baró, F., Berry, P., Termansen, M., Barton, D., Stange, E., Thoonen, M., Kalóczkai, Á., Vadineanu, A., Castro, A.J., Czúcz, B., Röckmann, C., Wurbs, D., Odee, D., Preda, E., Gomez-Baggethun, E.N., Rusch, G., Martínez Pastur, G., Palomo, I., Dick, J., Casaer, J., van Dijk, J., Priess, J., Langemeyer, J., Mustajoki, J., Kopperoinen, L., Baptist, M.J., Luis Peri, P., Mukhopadhyay, R., Aszalós, R., Roy, S.B., Luque, S., Rusch, V. (2017). When we cannot have it all: Ecosystem services trade-offs in real-life planning contexts. Ecosystem Services, 29, 566-578.

Uhde, B., Hahn, W.A., Griess, V.C., Knoke, T. (2015). Hybrid MCDA methods to integrate multiple ecosystem services in forest management planning: A critical review. Environmental Management, 56, 373-388. 
van der Meulen, E.S., Braat, L.C., Brils, J.M. (2016). Abiotic flows should be inherent part of ecosystem services classification. Ecosystem Services, 19, 1-5.

Voinov, A., Kolagani, N., McCall, M.K., Glynn, P.D., Kragt, M.E., Ostermann, F.O., Pierce, S.A., Ramu, P. (2016). Modelling with stakeholders - next generation. Environmental Modelling \& Software, 77, 196-220.

von Winterfeldt, D. (1980). Structuring decision problems for decision analysis. Acta Psychologica, 45, 71-93.

von Winterfeldt, D., Edwards, W. (1986). Decision Analysis and Behavioral Research. Cambridge University Press. 


\section{Appendix A. CICEC classification (V4.3) of ecosystem services}

Source: http://cices.eu

Section column lists the three main categories of ecosystem services

Division column divides section categories into main types of output or process.

The group level splits division categories by biological, physical or cultural type or process.

The class level provides a further sub-division of group categories into biological or material outputs and bio-physical and cultural processes that can be linked back to concrete identifiable service sources.

Class types break the class categories into further individual entities and suggest ways of measuring the associated ecosystem service output. Note: Class type section is open in that many class types can potentially be recognized and nested in the higher level classes, depending on the ecosystems being considered.

\begin{tabular}{|c|c|c|c|c|}
\hline \multicolumn{5}{|c|}{ CICES for ecosystem accounting } \\
\hline Section & Division & Group & Class & Class type \\
\hline \multirow{16}{*}{$\begin{array}{l}\text { Provisio- } \\
\text { ning }\end{array}$} & \multirow[t]{8}{*}{ Nutrition } & \multirow[t]{6}{*}{ Biomass } & Cultivated crops & Crops by amount, type \\
\hline & & & Reared animals and their outputs & Animals, products by amount, type \\
\hline & & & $\begin{array}{l}\text { Wild plants, algae and their } \\
\text { outputs }\end{array}$ & Plants, algae by amount, type \\
\hline & & & Wild animals and their outputs & Animals by amount, type \\
\hline & & & $\begin{array}{l}\text { Plants and algae from in-situ } \\
\text { aquaculture }\end{array}$ & Plants, algae by amount, type \\
\hline & & & Animals from in-situ aquaculture & Animals by amount, type \\
\hline & & \multirow[t]{2}{*}{ Water } & Surface water for drinking & By amount, type \\
\hline & & & Ground water for drinking & \\
\hline & \multirow[t]{5}{*}{ Materials } & \multirow[t]{3}{*}{ Biomass } & $\begin{array}{l}\text { Fibres and other materials from } \\
\text { plants, algae and animals for } \\
\text { direct use or processing }\end{array}$ & $\begin{array}{l}\text { Material by amount, type, use, } \\
\text { media (land, soil, freshwater, } \\
\text { marine) }\end{array}$ \\
\hline & & & $\begin{array}{l}\text { Materials from plants, algae and } \\
\text { animals for agricultural use }\end{array}$ & \\
\hline & & & Genetic materials from all biota & \\
\hline & & \multirow[t]{2}{*}{ Water } & $\begin{array}{l}\text { Surface water for non-drinking } \\
\text { purposes }\end{array}$ & By amount, type and use \\
\hline & & & $\begin{array}{l}\text { Ground water for non-drinking } \\
\text { purposes }\end{array}$ & \\
\hline & \multirow[t]{3}{*}{ Energy } & \multirow{2}{*}{$\begin{array}{l}\text { Biomass- } \\
\text { based ener- } \\
\text { gy sources }\end{array}$} & Plant-based resources & By amount, type, source \\
\hline & & & Animal-based resources & \\
\hline & & $\begin{array}{l}\text { Mechanical } \\
\text { energy }\end{array}$ & Animal-based energy & By amount, type, source \\
\hline
\end{tabular}




\begin{tabular}{|c|c|c|c|c|}
\hline Section & Division & Group & Class & Class type \\
\hline \multirow{21}{*}{$\begin{array}{l}\text { Regula- } \\
\text { tion \& } \\
\text { Mainte- } \\
\text { nance }\end{array}$} & \multirow{5}{*}{$\begin{array}{l}\text { Mediation } \\
\text { of waste, } \\
\text { toxics and } \\
\text { other } \\
\text { nuisances }\end{array}$} & \multirow[t]{2}{*}{$\begin{array}{l}\text { Mediation } \\
\text { by biota }\end{array}$} & $\begin{array}{l}\text { Bio-remediation by micro- } \\
\text { organisms, algae, plants, and } \\
\text { animals }\end{array}$ & $\begin{array}{l}\text { By amount, type, use, media (land, } \\
\text { soil, freshwater, marine) }\end{array}$ \\
\hline & & & $\begin{array}{l}\text { Filtration/sequestration/storage/a } \\
\text { ccumulation by micro-organisms, } \\
\text { algae, plants, and animals }\end{array}$ & $\begin{array}{l}\text { By amount, type, use, media (land, } \\
\text { soil, freshwater, marine) }\end{array}$ \\
\hline & & \multirow[t]{3}{*}{$\begin{array}{l}\text { Mediation } \\
\text { by } \\
\text { ecosystems }\end{array}$} & $\begin{array}{l}\text { Filtration/sequestration/ } \\
\text { storage/accumulation by } \\
\text { ecosystems }\end{array}$ & $\begin{array}{l}\text { By amount, type, use, media (land, } \\
\text { soil, freshwater, marine) }\end{array}$ \\
\hline & & & $\begin{array}{l}\text { Dilution by atmosphere, } \\
\text { freshwater and marine } \\
\text { ecosystems }\end{array}$ & \\
\hline & & & $\begin{array}{l}\text { Mediation of smell/noise/visual } \\
\text { impacts }\end{array}$ & \\
\hline & \multirow[t]{6}{*}{$\begin{array}{l}\text { Mediation } \\
\text { of flows }\end{array}$} & \multirow[t]{2}{*}{ Mass flows } & $\begin{array}{l}\text { Mass stabilisation and control of } \\
\text { erosion rates }\end{array}$ & By reduction in risk, area protected \\
\hline & & & $\begin{array}{l}\text { Buffering and attenuation of mass } \\
\text { flows }\end{array}$ & \\
\hline & & \multirow[t]{2}{*}{ Liquid flows } & $\begin{array}{l}\text { Hydrological cycle and water flow } \\
\text { maintenance }\end{array}$ & By depth/volumes \\
\hline & & & Flood protection & By reduction in risk, area protected \\
\hline & & \multirow{2}{*}{$\begin{array}{l}\text { Gaseous / } \\
\text { air flows }\end{array}$} & Storm protection & By reduction in risk, area protected \\
\hline & & & Ventilation and transpiration & By change in temperature/humidity \\
\hline & \multirow{10}{*}{$\begin{array}{l}\text { Maintenan- } \\
\text { ce of } \\
\text { physical, } \\
\text { chemical, } \\
\text { biological } \\
\text { conditions }\end{array}$} & \multirow{2}{*}{$\begin{array}{l}\text { Lifecycle } \\
\text { maintenan- } \\
\text { ce, habitat } \\
\text { and gene } \\
\text { pool } \\
\text { protection }\end{array}$} & Pollination and seed dispersal & By amount and source \\
\hline & & & $\begin{array}{l}\text { Maintaining nursery populations } \\
\text { and habitats }\end{array}$ & By amount and source \\
\hline & & \multirow{2}{*}{$\begin{array}{l}\text { Pest and } \\
\text { disease } \\
\text { control }\end{array}$} & Pest control & $\begin{array}{l}\text { By reduction in incidence, risk, area } \\
\text { protected }\end{array}$ \\
\hline & & & Disease control & \\
\hline & & \multirow{2}{*}{$\begin{array}{l}\text { Soil } \\
\text { formation } \\
\text { and } \\
\text { composition }\end{array}$} & Weathering processes & $\begin{array}{l}\text { By amount/concentration and } \\
\text { source }\end{array}$ \\
\hline & & & $\begin{array}{l}\text { Decomposition and fixing } \\
\text { processes }\end{array}$ & \\
\hline & & \multirow{2}{*}{$\begin{array}{l}\text { Water } \\
\text { conditions }\end{array}$} & Chemical condition of freshwaters & \multirow{2}{*}{$\begin{array}{l}\text { By amount/concentration and } \\
\text { source }\end{array}$} \\
\hline & & & Chemical condition of salt waters & \\
\hline & & \multirow{2}{*}{$\begin{array}{l}\text { Atmosphe- } \\
\text { ric compo- } \\
\text { sition and } \\
\text { climate } \\
\text { regulation }\end{array}$} & $\begin{array}{l}\text { Global climate regulation by } \\
\text { reduction of greenhouse gas } \\
\text { concentrations }\end{array}$ & \multirow[t]{2}{*}{$\begin{array}{l}\text { By amount, concentration or } \\
\text { climatic parameter }\end{array}$} \\
\hline & & & $\begin{array}{l}\text { Micro and regional climate } \\
\text { regulation }\end{array}$ & \\
\hline
\end{tabular}




\begin{tabular}{|c|c|c|c|c|}
\hline Section & Division & Group & Class & Class type \\
\hline \multirow[t]{11}{*}{ Cultural } & \multirow{7}{*}{$\begin{array}{l}\text { Physical and } \\
\text { intellectual } \\
\text { interactions } \\
\text { with biota, } \\
\text { ecosystems, } \\
\text { and land- } \\
\text { /seascapes } \\
\text { [environ- } \\
\text { mental } \\
\text { settings] }\end{array}$} & \multirow[t]{2}{*}{$\begin{array}{l}\text { Physical and } \\
\text { experiential } \\
\text { interactions }\end{array}$} & $\begin{array}{l}\text { Experiential use of plants, animals } \\
\text { and land-/seascapes in different } \\
\text { environmental settings }\end{array}$ & \multirow[t]{2}{*}{$\begin{array}{l}\text { By visits/use data, plants, animals, } \\
\text { ecosystem type }\end{array}$} \\
\hline & & & $\begin{array}{l}\text { Physical use of land-/seascapes in } \\
\text { different environmental settings }\end{array}$ & \\
\hline & & \multirow{5}{*}{$\begin{array}{l}\text { Intellectual } \\
\text { and repre- } \\
\text { sentative } \\
\text { interactions }\end{array}$} & Scientific & \multirow{5}{*}{$\begin{array}{l}\text { By use/citation, plants, animals, } \\
\text { ecosystem type }\end{array}$} \\
\hline & & & Educational & \\
\hline & & & Heritage, cultural & \\
\hline & & & Entertainment & \\
\hline & & & Aesthetic & \\
\hline & \multirow{4}{*}{$\begin{array}{l}\text { Spiritual, } \\
\text { symbolic } \\
\text { and other } \\
\text { interactions } \\
\text { with biota, } \\
\text { ecosystems, } \\
\text { and land- } \\
\text { /seascapes } \\
\text { [environ- } \\
\text { mental } \\
\text { settings] }\end{array}$} & \multirow{2}{*}{$\begin{array}{l}\text { Spiritual } \\
\text { and/or } \\
\text { emblematic }\end{array}$} & Symbolic & \multirow{2}{*}{$\begin{array}{l}\text { By use, plants, animals, ecosystem } \\
\text { type }\end{array}$} \\
\hline & & & Sacred and/or religious & \\
\hline & & \multirow[t]{2}{*}{$\begin{array}{l}\text { Other } \\
\text { cultural } \\
\text { outputs }\end{array}$} & Existence & \multirow[t]{2}{*}{$\begin{array}{l}\text { By plants, animals, } \\
\text { feature/ecosystem type or } \\
\text { component }\end{array}$} \\
\hline & & & Bequest & \\
\hline
\end{tabular}

